\title{
PENGARUH STRATEGI PEMBELAJARAN RECIPROCAL TEACHING TERHADAP HASIL BELAJAR MATEMATIKA SISWA KELAS IV MI NIDHOMIYAH JOMBANG
}

\author{
Faridatul Masruroh ${ }^{1)}$, Tomi Syafrudin ${ }^{2)}$ \\ ${ }^{1)}$ STKIP PGRI Jombang \\ ${ }^{2)}$ UNIPDU Jombang \\ Email: sinuslegowo@gmail.com
}

\begin{abstract}
Selection of appropriate learning strategies by teachers tailored to the subject matter, so that students can understand the subject clearly. Reciprocal Teaching is a learning strategy so that learning objectives are reached quickly through the process of independent learning. By presentation in front of a class, students are expected to achieve learning objectives and increase learning independence. This study aims to determine whether there is an influence of Reciprocal Teaching towards mathematics learning outcomes of fourth-grade students MI Nidhomiyah Jombang academic year 2018/2019. The calculation of the t-value uses SPSS 16. The result of $t$-value is 4,667 with sig ( 2 tailed $)=0,000$. The data result showed that $H_{0}$ is rejected. The researchers concluded that there is influence Reciprocal Teaching towards mathematics learning outcomes.
\end{abstract}

Keywords: Reciprocal teaching, Mathematics learning outcomes

\section{PENDAHULUAN}

Pendidikan adalah usaha sadar dan terencana untuk mewujudkan suasana belajar dan proses pembelajaran agar siswa secara aktif mengembangkan potensi dirinya untuk memiliki kekuatan spiritual keagamaan, pengendalian diri, kepribadian, kecerdasan, akhlak mulia, serta keterampilan yang diperlukan dirinya, masyarakat, bangsa dan negara (UU RI No. 20 Tahun 2003 tentang Sistem Pendidikan Nasional Bab I pasal 1 dalam Rohman, 2011).

Kline dalam Karso (Yuliana, 2012) mengatakan bahwa matematika bukan pengetahuan menyendiri yang dapat sempurna karena dirinya sendiri, tetapi keberadaannya terutama untuk membantu manusia dalam memahami dan menguasai permasalahan sosial, ekonomi dan alam. Setiap hari matematika digunakan oleh manusia dalam kehidupannya, seperti ketika menghitung banyaknya pengeluaran sehari-hari, mengukur, dan lain sebagainya. Mengingat betapa pentingnya matematika dalam kehidupan manusia, maka matematika perlu dikenalkan sedini mungkin. Pendidikan matematika pada jenjang pendidikan dasar merupakan pondasi yang sangat menentukan dalam membentuk sikap, kecerdasan, dan kepribadian anak. Sehingga perlu adanya kegiatan pembelajaran pada pendidikan matematika.
Pemilihan strategi pembelajaran yang tepat oleh guru disesuaikan dengan materi yang akan disampaikan sehingga siswa dapat memahami dengan jelas setiap materi yang disampaikan serta mampu membuat proses belajar menjadi lebih optimal dan mencapai keberhasilan. Salah satu strategi pembelajaran yang dapat diterapkan dalam pembelajaran matematika yaitu Reciprocal Teaching.

Reciprocal Teaching merupakan salah satu pendekatan pembelajaran yang dilaksanakan agar tujuan pembelajaran tercapai dengan cepat melalui proses belajar mandiri dan siswa mampu manyajikannya di depan kelas sehingga diharapkan tujuan pembelajaran tersebut tercapai dan kemampuan siswa dalam belajar mandiri dapat ditingkatkan. Reciprocal Teaching (pengajaran terbalik) adalah pendekatan pembelajaran yang dikembangkan melalui kegiatan mengajarkan teman sebaya yang bersifat kerjasama.

Garderen (Andayani, 2016) menyatakan bahwa pada pembelajaran matematika melalui Reciprocal Teaching siswa diajarkan empat strategi pemahaman yaitu merangkum materi pelajaran, memikirkan dan mengajukan pertanyaan dari apa yang tidak dimengerti, membuat langkah-langkah yang dibutuhkan dalam penyelesaian masalah matematika, dan mengklarifikasi bagian-bagian yang sulit. Dengan strategi pembelajaran Reciprocal Teaching, siswa menjadi lebih mandiri dan aktif 
dalam membangun pengetahuannya dengan guru sebagai fasilitator dan mediator dalam pembelajaran. Reciprocal Teaching adalah prosedur pengajaran atau pendekatan yang dirancang untuk mengajarkan kepada siswa tentang strategi-strategi kognitif dan untuk membantu siswa memahami dengan baik.

Pada strategi pembelajaran Reciprocal Teaching siswa akan menjadi lebih aktif dan kreatif dalam menemukan gagasan-gagasan baru dalam menyelesaikan permasalahan matematika dalam kegiatan belajar mengajar. Di samping itu siswa dapat mengomunikasikan gagasan/temuannya tersebut kepada siswa lainnya sehingga dapat menciptakan interaksi positif antar siswa di kelas tersebut. Penggunaan Reciprocal Teaching ini dalam pembelajaran diharapkan dapat bepengaruh terhadap hasil belajar matematika siswa pada materi bangun ruang. Materi bangun ruang dipilih karena pada materi bangun ruang hasil belajar siswa kurang optimal.

Menurut hasil penelitian Arifiyandy (2013), dalam penelitiannya yang berjudul peningkatan hasil belajar matematika melalui model Reciprocal Teaching pokok bahasan Teorema Phytagoras, hasil tes pada siklus I adalah $38,8 \%$ siswa yang tuntas dan hasil tes pada siklus II adalah $88,8 \%$ siswa yang tuntas, yang berarti bahwa pendekatan Reciprocal Teaching dapat meningkatkan hasil belajar matematika siswa.

Penelitian Kawedar (2012) yang berjudul penerapan model pembelajaran Reciprocal Teaching untuk meningkatkan hasil belajar siswa pada pokok bahasan segitiga siswa kelas VII-C SMP Negeri Kepanjen menyatakan bahwa hasil belajar matematika siswa kelas VII-C SMP Negeri 2 Kepanjen Malang dapat meningkat dengan menerapkan pendekatan Reciprocal Teaching. Terlihat dari hasil tes siklus I persentase siswa yang mendapat nilai minimal 75 adalah $87,5 \%$ padahal sebelum diberikan tindakan persentase siswa yang mendapatkan nilai minimal 75 adalah 44,5\% sehingga terjadi peningkatan sebesar $43,0 \%$.

Hasil penelitian Tatik pada tahun 2014 yang berjudul pengaruh pendekatan Reciprocal Teaching terhadap hasil belajar matematika siswa kelas VII MTs Al-Asy'ariyah tahun pelajaran 2013/2014 menjelaskan bahwa ada pengaruh pendekatan Reciprocal Teaching terhadap hasil belajar matematika siswa kelas
VII MTs Al-Asy'ariyah tahun pelajaran 2013/2014. Hal itu terlihat dari hasil perhitungan $t_{\text {hitung }}=2,345$ dan $t_{\text {tabel }}=1,99$ dengan taraf signifikansi sebesar $\alpha=5 \%$ hasil data tersebut menunjukkan bahwa $t_{\text {hitung }}>t_{\text {tabel }}$ yang mengartikan bahwa $\mathrm{H}_{0}$ ditolak.

Hasil dari tiga penelitian tersebut, dapat disimpulkan bahwa strategi pembelajaran Reciprocal Teaching tidak hanya dapat diterapkan di jenjang pendidikan atas, namun juga di jenjang pendidikan dasar guna melatih kemandirian siswa dalam merangkum materi pelajaran, memikirkan dan mengajukan pertanyaan dari apa yang tidak di mengerti, membuat langkah-langkah yang dibutuhkan dalam penyelesaian masalah matematika, dan mengklarifikasi bagian-bagian yang sulit. Sehingga peneliti berpendapat bahwa strategi pembelajaran Reciprocal Teaching akan berpengaruh pada hasil belajar matematika siswa kelas IV di MI Nidhomiyah Jombang.

Strategi pembelajaran Reciprocal Teaching merupakan salah satu pendekatan pembelajaran yang dilaksanakan agar tujuan pembelajaran tercapai dengan cepat melalui proses belajar mandiri dan siswa mampu menyajikan materi di depan kelas. Melalui Reciprocal Teaching, diharapkan tujuan pembelajaran tersebut tercapai dan kemandirian belajar meningkat.

Menurut Trianto dalam Afifah (2000), Reciprocal Teaching merupakan suatu pendekatan konstruktivis dengan menggunakan strategi belajar berbasis prinsip pembuatan/pengajuan pertanyaan dan ketrampilan belajar matematika siswa yang pemahamannya rendah. Hal ini dapat diartikan bahwa Reciprocal Teaching memiliki proses pembelajaran yang memungkinkan siswa lebih aktif dalam membangun pengetahuannya dengan guru sebagai fasilitator dan mediator dalam proses pembelajaran.

Dengan Reciprocal Teaching, guru mengajarkan keterampilan kognitif kepada siswa dengan menciptakan pengalaman belajar, melalui pemodelan perilaku tertentu. Selanjutnya guru membantu siswa mengembangkan keterampilan tersebut atas usaha mereka sendiri dengan pemberian semangat, dukungan dan suatu sistem scaffolding (Brown, dkk dalam Trianto, 2009). 
Scafffolding adalah bimbingan yang diberikan oleh orang yang lebih tahu kepada orang yang kurang tahu atau belum tahu. Melalui belajar kelompok siswa dapat berkembang lebih baik sehingga dicapai kemampuan potensialnya (Harahap dalam Tatik, 2014).

Reciprocal Teaching merupakan pendekatan pembelajaran yang sangat fleksibel dan mudah disesuaikan dengan kondisi kelas serta subjek pelajarannya. Sehingga, Reciprocal Teaching yang diperkenalkan oleh Palincsar dan Brown bukanlah harga mati ataupun rumus baku. Tahap-tahap pembelajaran Reciprocal Teaching dapat diubah alurnya sesuai dengan tujuan pembelajaran yang ingin dicapai. Merujuk pada Palincsar dalam Tatik (2014) alur yang digunakan pada pembelajaran yaitu summarizing - questioning - predicting clarifying. Empat strategi pemahaman yang digunakan pada pendekatan Reciprocal Teaching dapat dijelaskan sebagai berikut:

1. Merangkum ( Sumarizing)

Dalam strategi ini, siswa diminta membuat rangkuman dari materi yang telah dipahami.

2. Membuat pertanyaan ( Questioning)

Strategi bertanya untuk memantau atau mengevaluasi pemahaman siswa terhadap materi. Siswa dapat membuat pertanyaaan sendiri ataupun soal yang diajukan kepada diri sendiri kemudian menjawabnya. Informasi apa yang diketahui dan yang tidak diketahui. Hal inilah yang disebut metakognitif. Proses metakognitif memungkinkan siswa melakukan pengecekan kembali tentang informasi yang telah diperoleh dari proses belajar dan materi yang belum dikuasai dari keseluruhan konsep yang telah diajarkan.

3. Prediksi ( Predicting)

Pada tahap ini siswa diajak untuk menghubungkan pengetahuan yang sudah dimiliki dengan informasi yang baru diperoleh kemudian membuat prediksi berdasarkan gabungan informasi tersebut (Angela dalam Tatik, 2014). Dari uraian tersebut, jelas diketahui bahwa pada tahap ini diharapkan terjadi koneksi antara konsep yang baru dipelajarinya dengan yang sudah dimiliknya.

4. Mengklarifikasi ( Clarrifying)
Siswa membaca terlebih dahulu materi ajar yang diberikan guru kemudian mengklarifikasi atau menjelaskan kata-kata yang tidak familiar. Pada tahap klarifikasi, siswa yang bertugas sebagai pemimpin klarifikasi memimpin dan membimbing kelompoknya dalam mengklarifikasi materi serta bertanggung jawab selama diskusi berlangsung.

Adapun langkah-langkah pembelajaran reciprocal teaching diawali dengan siswa membaca suatu topik tertentu. Selanjutnya, guru memimpin, melaksanakan, dan memperagakan empat strategi reciprocal Teaching, yaitu menyimpulkan, membuat pertanyaan, mengklarifikasi, dan memprediksi. Dengan bimbingan guru, siswa berlatih menggunakan strategi tersebut. Selanjutnya siswa memimpin tanya jawab dengan atau tanpa adanya guru. Pada Reciprocal Teaching, peran guru adalah memberi contoh, scaffolding, umpan balik, memberi penjelasan, sebagai fasilitator dan memotivasi siswa untuk terlibat aktif dalam pembelajaran. Berdasarkan hal tersebut, berarti guru dan siswa harus saling bekerjasama dalam kegiatan pembelajaran, sehingga siswa dapat memahami materi dengan baik.

\section{METODE}

Penelitian ini termasuk penelitian kuantitatif dengan metode penelitiannya adalah metode eksperimen. Penelitian eksperimen dapat diartikan sebagai metode penelititan yang digunakan untuk mencari pengaruh perlakuan tertentu terhadap subjek penelitian dalam kondisi yang terkendalikan, karena dalam penelitian eksperimen ada perlakuan (treatment) (Sugiyono, 2013). Peneliti menggunakan rancangan penelitian One-Group Pretest-Posttest Design. Dalam penelitian ini, peneliti menggunakan dua variabel, yaitu variabel bebas dan variabel terikat. Variabel bebas yaitu strategi pembelajaran Reciprocal Teaching, sedangkan variabel terikat yaitu hasil belajar matematika siswa. Subjek penelitian adalah seluruh siswa kelas IV MI Nidhomiyah Jombang berjumlah 39 siswa, terdiri dari 2 kelas paralel yaitu IVA dan IVB.

Instrumen penelitian adalah lembar tes hasil belajar yang digunakan untuk memperoleh data berupa hasil belajar siswa pada materi bangun ruang. Adapun tes hasil belajar siswa 
akan diuji tingkat validitas dan reliabilitasnya. Pengujian validitas menggunakan rumus korelasi product moment

$$
r_{x y}=\frac{N \sum X Y-\left(\sum X\right)\left(\sum Y\right)}{\sqrt{\left[N \sum X^{2}-\left(\sum X\right)^{2} \| N \sum Y^{2}-\left(\sum Y\right)^{2}\right]}} .
$$

Sedangkan pengujian reliabilitas menggunakan rumus Alpha $r_{11}=\left[\frac{k}{k-1}\right]\left[1-\frac{\sum \sigma_{b}^{2}}{\sigma_{t}^{2}}\right]$. Langkah berikutnya soal yang telah memenuhi syarat, dapat diberikan kepada subjek penelitian. Tes yang telah dikerjakan siswa kemudian diuji normalitasnya. Data yang berdistribusi normal selanjutnya dilakukan uji $\mathrm{t}$ dengan rumus $t=$ $\frac{M d}{\sqrt{\frac{\sum x_{d}^{2}}{N(N-1)}} .}$

\section{HASIL DAN PEMBAHASAN}

Peneliti mempersiapkan perangkat penelitian yakni berupa Rencana Pelaksanaan Pembelajaran (RPP) dan lembar tes hasil belajar yang telah divalidasi tiga validator. Selanjutnya, tes hasil belajar diujikan ke kelas IV A di MI Nidhomiyah Jombang, dan didapatkan hasil sebagai berikut.

Tabel 1. Hasil Uji Validitas Pre-Test dan PostTest

\begin{tabular}{ccccc}
\hline $\begin{array}{c}\text { Soal } \\
\text { ke- }\end{array}$ & $\begin{array}{c}\text { Soal } \\
\text { Pre- } \\
\text { Test }\end{array}$ & $\begin{array}{c}\text { Tingkat } \\
\text { Validitas }\end{array}$ & $\begin{array}{c}\text { Soal } \\
\text { Post- } \\
\text { Test }\end{array}$ & $\begin{array}{c}\text { Tingkat } \\
\text { Validitas }\end{array}$ \\
\hline $\begin{array}{c}\text { Soal } \\
1\end{array}$ & 0,624 & Kuat & 0,647 & Kuat \\
$\begin{array}{c}\text { Soal } \\
2\end{array}$ & 0,656 & Kuat & 0,691 & Kuat \\
$\begin{array}{c}\text { Soal } \\
3\end{array}$ & 0,653 & Kuat & 0,735 & Kuat \\
$\begin{array}{c}\text { Soal } \\
4\end{array}$ & 0,544 & Sedang & 0,440 & Sedang \\
$\begin{array}{c}\text { Soal } \\
5\end{array}$ & 0,556 & Sedang & 0,657 & Sedang \\
\hline
\end{tabular}

Hasil uji reliabilitas soal pre-test dihitung dengan bantuan program SPSS versi 16. Hasil uji reliabilitas pre-test ditampilkan pada tabel berikut.

Tabel 2. Hasil Uji Reliabilitas Pre-Test

$\begin{array}{rrr}\text { Cronbach's Alpha } & \text { N of Items } & \\ .437 & & 5\end{array}$

Hasil uji reliabilitas soal post-test dihitung dengan bantuan program SPSS versi 16. Hasil uji reliabilitas post-test dapat dilihat pada tabel di bawah ini.
Tabel 3. Hasil Uji Reliabilitas Post-Test

\begin{tabular}{rr}
\hline Cronbach's Alpha & N of Items \\
\hline .592 & 5 \\
\hline
\end{tabular}

Dari tabel 2 diperoleh koefisien reliabilitas $r_{11}=0,437$, berada pada selang $0,40-0,599$, dimana tingkat reliabilitasnya termasuk kategori sedang. Berarti, instrumen pada soal pre-test adalah reliabel. Selanjutnya, pada tabel 3, terlihat bahwa koefisien reliabilitas $r_{11}=0,592, \quad$ dimana tingkat reliabilitasnya sedang yakni berada pada selang $0,40-0,599$. Berarti, instrumen pada soal posttest adalah reliabel. Jadi, dari uji validitas dan reliabilitas tersebut, dapat disimpulkan bahwa instrumen tes yang digunakan telah memenuhi syarat valid dan reliabel. Oleh karena itu, instrumen tes dapat digunakan untuk memperoleh data dalam penelitian.

Setelah dilakukan uji validitas dan reliabilitas, selanjutnya dilakukan uji normalitas. Hasil pengujian normalitas dengan menggunakan SPSS disajikan pada tabel 4 berikut.

Tabel 4. Uji Normalitas Nilai Pretest dan Posttest

\begin{tabular}{|c|c|c|c|}
\hline & & $\begin{array}{c}\text { NILAI_ } \\
\text { PRE_T } \\
\text { EST }\end{array}$ & $\begin{array}{l}\text { NILAI } \\
\text { _POST } \\
\text { _TEST }\end{array}$ \\
\hline $\mathrm{N}$ & & 21 & 21 \\
\hline Normal & Mean & 67.48 & 83.38 \\
\hline & Std. Deviation & 21.108 & 12.010 \\
\hline Most & Absolute & .215 & .209 \\
\hline $\begin{array}{l}\text { Extreme } \\
\text { Differences }\end{array}$ & Positive & .159 & .209 \\
\hline & Negative & -.215 & -.190 \\
\hline Kolmogorov & Smirnov Z & .986 & .959 \\
\hline Asymp. Sig. & (2-tailed) & .285 & .316 \\
\hline
\end{tabular}

a. Test distribution is

Normal.

b. Calculated from data.

Berdasarkan hasil perhitungan pada output SPSS diperoleh nilai pre-test Asymp. Sig. $(2$-tailed $)=0,285$ dan nilai post-test Asymp . Sig. $(2$-tailed $)=0,316$ yang berarti nilai ini lebih besar dari taraf signifikansi $(\alpha=0,05)$ 
yang diajukan, maka $H_{0}$ diterima, artinya data berdistribusi normal.

Pengujian rata-rata dilakukan dengan menggunakan SPSS. Dari hasil output SPSS diperoleh nilai t sebesar 4,667 dengan sig (2tailed $)=0,000$. Hal ini menunjukkan bahwa nilai sig $<0,05$ yang mengartikan bahwa $H_{0}$ ditolak. Dengan demikian dapat disimpulkan bahwa ada pengaruh strategi pembelajaran Reciprocal Teaching terhadap hasil belajar matematika siswa.

\section{SIMPULAN}

Terdapat pengaruh strategi pembelajaran Reciprocal Teaching terhadap hasil belajar matematika siswa. Hal ini dapat dilihat dari hasil perhitungan nilai $\mathrm{t}$ sebesar 4,667 dengan $\operatorname{sig}(2$-tailed $)=0,000$ lebih kecil daripada $\alpha=$ 0,05 . Hasil data tersebut menunjukkan bahwa nilai sig $<0,05$ yang mengartikan bahwa $H_{0}$ ditolak.

Dengan demikian perlu diperhatikan dalam melaksanakan strategi pembelajaran Reciprocal Teaching perlu memperhatikan

1. Dalam melaksanakan pembelajaran matematika dengan Reciprocal Teaching sebaiknya siswa bekerjasama dengan baik antar teman kelompok, agar materi yang didapat dari hasil diskusi dapat dipahami.

2. Dengan Reciprocal Teaching seharusnya siswa menjadi mandiri dan berani untuk memaparkan hasil diskusi didepan kelompok yang lain.

3. Pada pelaksanaan pembelajaran, seorang guru hanya menjadi fasilitator, motivator, serta pembimbing yang baik untuk membantu siswa yang mengalami kesulitan agar siswa daapat membangun pengetahuannya sendiri.

4. Berdasarkan hasil penelitian ini, diharapkan sekolah tidak hanya menjadikan penelitian ini sebagai bahan pengetahuan saja, bahwa strategi pembelajaran Reciprocal Teaching mampu meningkatkan hasil belajar matematika siswa, melainkan juga menerapkannya dalam pembelajaran mata pelajaran yang lain.

5. Selama proses penelitian berlangsung tampak bahwa siswa kurang percaya diri dalam menjalankan peran sebagai guru di depan teman-temannya. Diterapkannya
Reciprocal Teaching dalam proses pembelajaran diharapkan mampu meningkatkan rasa percaya diri siswa serta mampu melatih kemandiriannya, dengan guru hanya menjadi fasilitator dan motivator saja.

\section{DAFTAR PUSTAKA}

Afifah, L. (2012). Efektivitas penggunaan model reciprocal teaching dengan melakukan fieldtrip terhadap hasil belajar matematika. Skripsi tidak diterbitkan. Semarang: Fakultas Tarbiyah IAIN Walisongo Semarang

Andayani, S. (2016). Implementasi model pembelajaran reciprocal teaching untuk meningkatkan kemampuan berpikir kritis dan hasil belajar. Aksioma, 5(2), 172 - 179

Arifiyandy, R.G. (2013). Peningkatan hasil belajar matematika melalui model Reciprocal Teaching pokok bahasan teorema phytagoras siswa kelas VIII Semester I SMP Negeri 2 Porong. Skripsi tidak diterbitkan. Malang: Pendidikan Ilmu Eksata dan Keolaragaan IKIP Malang

Ferryansyah. (2011). Perbandingan prestasi belajar matematika siswa antara pembelajaran yang disertai penciptaan kondisi alfa dan tanpa disertai penciptaan kondisi alfa. Jurnal Ilmu-Ilmu Sosial, 3 (2). $235-242$

Kawedar, W.P. dan Qohar, A. (2012). Penerapan model pembelajaran reciprocal teaching untuk meningkatkan hasil belajar siswa pada pokok bahasan segitiga siswa kelas VII-C SMP Negeri 2 Kapanjen. Jurnal Online UM, 1(2).

Rohman, M.A. (2011). Pengaruh Penguasaan Konsep Bangun Datar Terhadap Kemampuan Menyelesaikan Soal Dalam Materi Pokok Bangun Ruang Pada Peserta Didik Kelas IX Semester Gasal Di MTs Mathalibul Huda Mlonggo Jepara Tahun Pelajaran 2011/2012. Skripsi tidak diterbitkan. Semarang: Fakultas Tarbiyah IAIN Walisongo Semarang 
PRINSIP Pendidikan Matematika

Volume 1, Nomor 2, Mei 2019 Sugiyono. (2013). Metode
kuantitatif, Kenelitian
Kulitatif, Dan $R \quad \& \quad D$. Bandung: Alfabeta

Tatik. (2014). Pengaruh pendekatan reciprocal teaching terhadap hasil belajar matematika siswa kelas VII MTS. AlAsy'ariyah. Jombang: Program Studi Pendidikan Matematika STKIP PGRI Jombang.
Trianto. (2009). Mendesain model pembelajaran inovatif-progresif. Surabaya: Kencana

Yuliana (2012). Pengaruh Penerapan TGT Terhadap Hasil Belajar Pada Pembelajaran Matematika Kelas IV SDN 11 Ponkot. Skripsi tidak diterbitkan. Pontianak: FKIP Universitas Tanjung Pura 